\title{
Collapse analysis of a venlo greenhouse by heavy snow hazard
}

\author{
Fengqi Zhu ${ }^{1, \text { a }}$ \\ ${ }^{1}$ Southeast University, Nanjing 210000, China \\ afengqizhu_seu@qq.com
}

Keywords: venlo greenhouse, heavy snow hazard, collapse, structural identification

Abstract. During the spring festival in 2013, a venlo greenhouse was collapsed due to the heavy snow hazard occurred in the south of Jiangsu, China. The greenhouse was analyzed by application SAP2000 finite element software and the conclusion of identification was presented by the present code and specification. At last, the current problem of venlo greenhouse design and construction in our country is discussed, and a good reference of reasonable design and construction is provided for this type structure.

\section{Introduction}

Venlo style greenhouse, originated from a town named Venlo, is a dual-slope green house featured by easy installation, high transmittance, small-sectioned component, less steel spending, good sealing, large ventilated area, and high degree of industrialization. Venlo style greenhouse is broadly applied in the fields like aquaculture, seedling of flower and vegetables, production and buildings like ornamental greenhouse, eco-greenhouse restaurant, making it the most widely used greenhouse structure in the world. The greatest advantage of Venlo style greenhouse lies in its high transmittance. Roof of 26.5 inclination (maximum sunshine incidence) with reduced, shrunk sized component and small-sectioned aluminum alloy extrusions to replace components of light steel glass greenhouse has significantly decreased shading of the bearing component. When introduced to China, shade net is added at its top in order to adapt the climate here. Besides cooling system composed of fans and drenchers that are installed at interior house in summer; while in winter, heating system made up of a large number hot-water pipes and spread in the interior greenhouse is utilized to protect it from low temperature for non-stop production throughout the year. However, it is the light small-sectioned component that causes poor overload capacity. Therefore, accident is prone to appear when it is overwhelmingly overloaded. Meanwhile, the inside cooling and heating system of Venlo style greenhouse applied in China allows a considerable load for structure. As a result, there exists great potential safety hazard in China for greenhouse structure that is still designed according to specification of Venlo style greenhouse [1].

In recent years, China is frequently subjected to climate disaster. Snow hazard every time will inflict extensive damage on light-steel construction. Safety and quality identification keeps growing accordingly with the increasing number of Venlo style greenhouse. The damage of Venlo style greenhouse in snow hazard, generally speaking, is caused by overloaded snow and poor resistance. The damage forms are roughly divided into bended roof purlin, deformed or cracked roof slab; detached roof slab and prilin with non-collapsed framework, twisted or extracted steel column base; overall collapse of the construction resulting from gravely distorted steel truss, steel columns, purlins and wall beam [2].

\section{Instance of engineering}

A flower culturing greenhouse, which is equipped with thin-film solar cell and grid-connected power station, has adopted self-controlled glass greenhouse of Venlo style with steel construction as its main body including truss, column, column brace, wall beam. The greenhouse, which will be completed by the end of 2010, shapes as triangle in its top and components like purlin, roof, gutter are made from 
aluminum alloy. The size of its plane axis is $132 \mathrm{~m} \times 64.1 \mathrm{~m}$ and the column axis $12 \mathrm{~m} \times 4 \mathrm{~m}$ folding back southwest. The layout of a total construction area of $800 \mathrm{~m} 2$ is presented as the chart, which is classified into A, B, C, D based on different size. Trusses, columns all employ Q235 steel with rectangle-shaped section bars and the roof, gutter, purlin 6063A-T5 aluminum alloy material with special section. The roof is equipped with solar panels and glass for the sake of power generation and lighting[3]. NEN3859 and NPR3860 greenhouse standards of Dutch are taken as reference when designing the bearing capacity of the main structure. The main parameters: fundamental wind pressure of $0.44 \mathrm{KN} / \mathrm{m} 2$, reference snow pressure of $0.25 \mathrm{KN} / \mathrm{m} 2$, no less than twenty years of service life. A sudden blizzard rendered the greenhouse into collapse during Spring Festival in 2013.

\section{Recheck of the design}

Firstly, establish finite element model. Then analyze the maximum vertical displacement of components in common usage utmost state as well as stress of components in bearing capacity limit state. Finally, recheck and compute the significant security risk found during the process of detecting the column base.

\section{A. Finite element analysis}

Modeling of the Venlo style greenhouse is analyzed via SAP2000 V14.2.4 finite element software. Glass and solar panels on the roof are simplified into uniform load simulation, interior wall pipes of heating system, sprinkling pipe system of the roof, windmills are installed at the models' nodes through concentrated force load. Other components all adopt elastic beam element to model strictly in accordance with section size and designed length. On-site test reveals that the connection of the column fixed by two anchor bolts is weak on the basis of hinged support simulation. Materials for struts between columns, supporting trusses of the roof, coupling beams between walls and columns are namely Q235, Q345 and 6063A-T5 for roof purlins, ridges and gutters. During the process of structural recheck by virtue of finite unit, group structural dead load, live load, snow load, wind load, temperature load effect by virtue of bearing capacity and common usage limit stage in accordance with load code for the design of building structure [3], and Greenhouse structure design load [4]. And then check and compute the most disadvantageous load effect with possible design situation concerned.

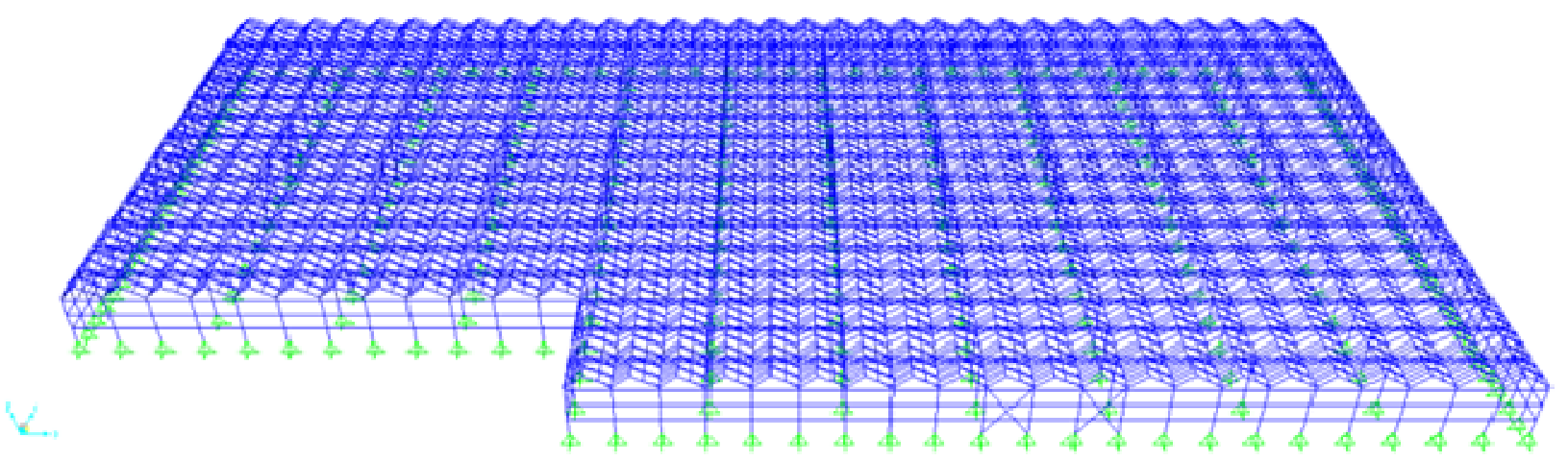

Figure1. finite element mode

B .Maximum vertical displacement of the joints

In the light of finite element analysis, displacement value of the joints of the main truss, purlin, gutter is figured out under control combinations of 1.0D+1.0L (1.0 dead load standard value +1.0 live load standard value)、1.0D+1.0S(dead load standard value $1.0+1.0$ uniform snow load standard value)、 1.0D+1.0S1(1.0 dead load standard value + 1.0 uneven snow load standard). Code for design of steel structure shows that defection value of truss reaches $\mathrm{L} / 400 \mathrm{~mm}$, ridges and gutters $\mathrm{L} / 200 \mathrm{~m}$ according 
to Code for design of aluminum alloy structure [5,6]. As presented in the table of maximum vertical displacement, defection values of the major truss, purlin, gutter are all within allowable limit.

Table1. Maximum vertical displacement of the components

\begin{tabular}{|c|c|c|c|c|c|}
\hline \multicolumn{2}{|l|}{ item } & major truss, & purlin & gutter & ridge \\
\hline \multirow{3}{*}{$\begin{array}{l}\text { Calculation value under different load } \\
\text { conditions }\end{array}$} & $1 \mathrm{D}+1 \mathrm{~L}$ & -26.57 & -7.91 & -5.75 & -1.45 \\
\hline & $1 \mathrm{D}+1 \mathrm{~S}$ & -22.17 & -6.52 & -4.77 & -1.22 \\
\hline & $\begin{array}{c}1 \mathrm{D}+1 \mathrm{~S} \\
1\end{array}$ & -25.45 & -7.45 & -5.49 & -1.33 \\
\hline \multicolumn{2}{|l|}{ specification limit } & 30 & $8 / 12 *$ & 16 & 16 \\
\hline
\end{tabular}

Note: $* 8 \mathrm{~mm}$ and $12 \mathrm{~mm}$ are defection values of aluminum Alloy purlin under glass pane and solar panel respectively

\section{C .stress ratio}

In the limit state of bearing capacity, design steel frame and aluminum alloy frame, compute stress ratio, and measure structural performance of the bars according to Code for design of steel structure and Code for design of aluminum alloy structure within SAP2000. As shown by the result, stabilized stresse of column $\mathrm{E}$ is utterly out of stress and stress ratio of column $\mathrm{C}$ and truss exceeds.

Table2. stress ratio of the components

\begin{tabular}{|c|c|c|}
\hline Name & Maximum stress ratio & Overrun ratio* \\
\hline Column A & 0.683 & $0 \%$ \\
\hline Column B & 0.876 & $0 \%$ \\
\hline Column C & 1.562 & $79.70 \%$ \\
\hline Column E & 1.711 & $100 \%$ \\
\hline upper chord & 1.228 & $2.03 \%$ \\
\hline Lower chord & 1.39 & $14.20 \%$ \\
\hline Web member & 1.35 & $34.50 \%$ \\
\hline ridge gutter, purlin & 0.64 & $0 \%$ \\
\hline
\end{tabular}

Note: Overrun ratio refers to the percentage of the components whose tress ratio is over 1.0

\section{Identification Result}

Combining the on-site detection and structural recheck results of the Venlo style greenhouse and its damage forms, it is clearly indicated that the collapse are caused mainly by middle column base E failure, out-of-plane stability of upper and lower chord, yield failure of web member, and further overall instability. The major instability forms: mutual function of wind load and snow load toward structure $\rightarrow$ out-of-plane stability led by middle column base $\mathrm{E}$ failure $\rightarrow$ failure of web, upper and lower cord member of the middle roof $\rightarrow$ invalid truss and joints of column $\mathrm{E} \rightarrow$ large area failure of the middle part of the roof $\rightarrow$ instability of column $\mathrm{C}$ and column base damage $\rightarrow$ intensify roof collapse $\rightarrow$ damage the column $\mathrm{A}, \mathrm{B} \rightarrow$ the whole structure goes out of effect $\rightarrow$ the greenhouse collapses.

Two grave consequences of column E failure: first, truss span increases once middle part of the truss goes out of effect, which sharply weakens bend-resist ability of the whole truss; Suddenly extended effective length brought by lost lateral restraints plus insufficient slenderness ratio of the web member itself result in instability of the whole truss. Second, column E failure could inevitably bring about excessive displacement and deformation of column cap both vertical and horizontal. Then the roof system around it losses constraints, which could easily make joints of the corresponding area out of effect.

The following part will analyze reasons of the collapse from design and construction. As for the aspect of design: 1) Standard snow load of greenhouse $0.25 \mathrm{KN} / \mathrm{m} 2$ in NEN3859 and NPR3860 of Dutch is 
smaller than once-in-50-years snow load $0.35 \mathrm{KN} / \mathrm{m} 2$ of this region set by architectural structure load standards and Greenhouse structure design load. 2) There are lots of unreasonable configuration of the components, excess slenderness ratio, unqualified bearing capacity in the original design. In terms of construction: there're six bolts to connect column base and foundation anchor in side pillars originally while in practice only two are used, which fails to meet the specification, and $\varphi 10$ round steel bars are adopted, which is inconsistent with the original 12 by design. 3) Some of bolts, nuts, washers in column bases are missed, unscrewed, or extracted from bolt holes, which dose not meet the design requirements.

\section{Conclusion}

1) The actual situation in China must be taken into consideration when introducing excellent foreign experiences. Overload claims the principal responsibility for this collapse by blindly coping the standard snow load of greenhouse in Dutch which is smaller than China's.

2 Design must be strictly abided by during construction. Amount of expansion bolts in the column base are obviously cut down--- originally-designed six column bolts and foundation anchor are reduced to one or two in practice when building the greenhouse, which easily results in instability of pillars in large load.

3) Warning system against snow hazard must be established so that action could be taken expeditiously and the snow on the roof could be cleared afterward.

\section{References}

[1] Shengning Lan, Xingu Zhong. Damage diagnose and lessons learnt from the failure of lightsteel structure by heavy snow in Xiangtan [J]. China Civil Engineering Journal, Vol.42 (3), 2009, p. 71-75.

[2] Ping Jiang. A case of structural identification of monolayer steel structure workshop [J]. Steel Structure, Vol.27 (5), 2012, p. 40-43.

[3] GB 50009-2012 Load code for the design of building structure [S].

[4] GB/T 18622-2002 Greenhouse structure design load [S].

[5] GB 50017-2003 Code for design of steel structures [S].

[6] GB 50429-2007 Code for design of aluminum alloy structure [S]. 